\title{
A NATUREZA DA REPRESENTAÇÃO ETNOGRÁFICA E A PRODUÇÃO DE CONHECIMENTO ANTROPOLÓGICA NA WEB
}

\author{
Ana Luiza Carvalho da Rocha
}

Cornelia Eckert ${ }^{1}$

"Sei que este homem meteu vários bisontes neste livro. Eu estava lá quando ele o fez e, desde então,
eu nunca mais tornei a ver bisontes." ( BRUHL, Lévy. Les Functions mentales dans sociétés inférieurs. 1910, p. 42)

A rede mundial de computadores forma uma comunidade real, denominada de ciberespaço, conformada por pessoas que podem interagir entre elas, em tempo real, independentemente da distancia física que as separa. Neste meio global, descentralizado e sem fronteiras, sujeito a interesses econômicos e financeiros, o controle sobre o uso de imagens, muitas delas protegidas por leis nacionais e internacionais, tais como aquelas tuteladas pelos direitos autorais, tem sido freqüentemente posto em debate. Particularmente, um tal sistema de intercomunicação por computadores e/ou por redes de computadores se não tem sido negligenciado como possibilidade de produção de novas escritas etnográficas, ao menos tem despertado interesse como objeto de estudo por antropólogos que estudam as modernas sociedades complexas.

É no bojo desta temática que surgiu o Projeto Coleções etnográficas, itinerários urbanos e patrimônio etnológico: a criação de um museu virtual ${ }^{2}$, no âmbito do Projeto Integrado Estudo antropológico de itinerários urbanos, formas de sociabilidade e memória coletiva no mundo contemporâneo $^{3}$, desenvolvido por mim em conjunto com a Profa. Cornelia Eckert, junto ao Laboratório de Antropologia Social do Programa de Pós-Graduação em Antropologia Social da Universidade Federal do Rio Grande do Sul; e que deu origem a criação do Banco de Imagens e Efeitos Visuais/BIEV. Desde suas origens o Banco de Imagens e Efeitos Visuais/BIEV se dirige à criação de narrativas etnográficas com base nas novas tecnologias eletrônicas e digitais e a sua circulação na Internet na forma de um banco de dados etnográficos sobre a cidade de Porto Alegre.

Configurados na modalidade de coleções etnográficas, o BIEV reúne documentos textuais, visuais e sonoros antigos e recentes da cidade de Porto Alegre, oriunda dos projetos de

\footnotetext{
${ }^{1}$ Este artigo é fruto de inúmeras contribuições de bolsistas de iniciação científica CNPq e FAPERGS, bolsistas de apoio técnico CNPq e pesquisadores associados CNPq e CAPES que contribuíram ou têm contribuído, desde 1998, com o seu trabalho para a realização da pesquisa do Banco de Imagens e Efeitos Visuais. Em especial gostaríamos de agradecer as colaborações de Rosana Pinheiro Machado, Olavo Ramalho Marques, Rafael Devos, Patrícia Rodolpho, Viviane Vedana, Fernanda Rechenberg, Paula Biazus, Luciana de Mello, Thais Cunegatto, Rafael Derois, Vanessa Zamboni, entre outros.

${ }^{2}$ Este projeto individual de pesquisa vem sendo financiado pelo CNPq, desde 1998, através de dotação de bolsas produtividade em pesquisa e de iniciação científica, e pela Fapergs, através de bolsa de iniciação científica.

${ }^{3}$ O referido Projeto Integrado de Pesquisa desenvolveu suas ações de pesquisa de 1998 a 2004. Em 2005, o Projeto terminou, e o Banco de Imagens e Efeitos Visuais tornou-se um grupo de pesquisa no interior do Núcleo de Estudos sobre Culturas Contemporâneas/NUPECs, junto ao PPGAS/UFRGS, reunindo-se as pesquisadores seniors os demais pesquisadores associados, com formação em Mestrado e Doutorado em Antropologia Social.
} 
investigação de seus pesquisadores e bolsistas no contexto da vida urbana local. Tais coleções de imagens encontram-se agrupadas em 4 bases de dados segundo seus diferentes suportes (textos, fotografias, vídeos e sons) e, apenas posteriormente irão a configurar o banco de dados do BIEV, apresentado, apresentado, em 2 modalidades: BIEV-data, posto-fixo-de-consulta, onde se encontra situado o Banco de Imagens e Efeitos Visuais (sala 108 do prédio do Instituto Latino-americano de Estudos Avançados/ILEA, no Campus do Vale/UFRGS), e BIEV-site, disponível aos usuários da Internet através do endereço eletrônico www.estacaoportoalegre.ufrgs.br.

$\mathrm{Na}$ criação do museu virtual, a imagem fotográfica assume posição de destaque, configurando-se como central na construção de seu núcleo semântico, e em torno da qual se formaram as outras 3 bases de dados (som, vídeo e escrita). Tendo-se, portanto, a fotografia no centro de uma constelação, todos os outros documentos etnográficos, escritos e audiovisuais, são classificados e catalogados, segundo suas fontes e em conformidade com determinadas categorias interpretativas e palavras chaves, previamente definidas em função dos temas de pesquisas que deram origem ao Banco de Imagens e Efeitos Visuais. No BIEV-data, toda fotografia é cadastrada conforme uma, e apenas uma categoria, ação que a coloca dentro de um lugar especifico no interior do sistema de classificação que conforma a base de dados do museu virtual. Além disto, ela precisa estar associado a mais de 6 tipos de palavras-chaves, o que faz com que uma fotografia, no momento do resgate de suas informações, faça parte de um conjunto de outros documentos que lhe foram associados, a partir destas palavras-chaves, através de determinados "nós" semânticos. No interior desta base de dados, a todo documento fotográfico cadastrado imediatamente associa-se a ele uma crônica visual (vídeo curto de 15' a 30'), uma coleção de escritos etnográficos e sons, com a intenção de propor ao usuário outros aspectos descritivos e interpretativos da memória coletiva e da estética urbana da cidade de Porto Alegre. Assim, os laços hipertextos que reúnem os documentos entre si na base de dados do BIEV-data, estabelecem relações não lineares entre eles, segundo as especificidades das formas disponíveis do usuário, através da tela de consulta, recuperar seu conteúdo de origem.

$\mathrm{O}$ acesso às coleções etnográficas do BIEV-data tanto quanto no BIEV-site adotam, portanto, a modalidade de laços tipificados segundo as formas de tratamento espaço-temporal (oposição, contigüidade, continuidade, etc.) que a pesquisa do fenômeno da memória coletiva e do patrimônio etnológico no mundo urbano contemporâneo que se desenvolve no Banco de Imagens e Efeitos Visuais. Na pesquisa da engenharia do texto eletrônico aplicada ao estudo do estatuto da representação etnográfica no âmbito da rede mundial de computadores, resulta a criação de formas diferenciais de exposição das coleções etnográficas: o BIEV-data na 
modalidade de posto-fixo-de-consulta e o BIEV-site (www.estacaoportoalegre.ufrgs.br), para ser veiculada na rede mundial de computadores.

Portanto, a estrutura da rede de laços e "nós" proposta para o percurso na base de dados de coleções etnográficas reunidas pelo BIEV-data, e a disponibilizada na Internet, através do BIEV-site, diferenciam-se na medida em que, na $W E B$, a interface de consulta parte de um mosaico de imagens da cidade de Porto Alegre em diferentes épocas que o usuário-internauta ativa, conforme a escolha de um tema e sub-temas, gerando-se disto algumas relações possíveis entre os seus conjuntos de documentos. No caso do BIEV-data, o conjunto de documentos etnográficos são acessados através de categorias, de palavras-chaves e de descritores, e até mesmo dos dados de suas fonte; no caso do BIEV-site (www.estacaoportoalegre.ufrgs.br), operase com outro sistema de arranjo documental a partir de 4 grandes núcleos semânticos descritivos da memória da cidade de Porto Alegre: cenários, artefatos, lugares e personagens, cada um deles contendo subdivisões de classificação.

A composição e o arranjo no interior das coleções etnográficas do BIEV-data tanto quanto do BIEV-site, obedece até certo ponto à lógica dos laços profundos, automáticos e interiores criados entre os documentos etnográficos que foram editados por todo aquele que trabalha na formação destas bases de dados e, posteriormente colocados para o usuário, no interior de um mesmo ambiente de consulta. Entretanto, tais laços hipertextuais são dependentes de outros laços que, por serem exteriores e ativáveis pelo usuário-internauta lhe permitem mudar de ponto de vista narrativo, escolher seu próprio ritmo de leitura até chegar a operar leituras múltiplas, divergentes, tensionais, contraditórias, repetitivas, etc. nos termos dos seus laços originais.

Importante se ressaltar que os documentos visuais e sonoros que configuram as coleções de documentos etnográficos que fazem parte da base de dados do BIEV-data foram todos eles reproduzidos de sua forma analógica para as formas digital e eletrônica, e tendo todos eles origens diversas (reproduções de imagens antigas e recentes obtidas em suportes diversos tais como fotografias, livros, revistas, jornais, filmes, vídeo, etc. além daquelas produzidas já em suporte digital e eletrônico).

\section{A deslinearização da narrativa etnográfica}

Como depositário de uma base de dados eletrônicos e digitais cuja originalidade reside no seu método de tratamento, seleção e disponibilização de fragmentos sonoros, escritos e visuais os mais diversos que configuram a memória coletiva de Porto Alegre, o BIEV opera, assim, com uma razoável quantidade de obras que estão protegidas pelos direitos autorais. 
Preocupados com esta questão para o caso do processo de compilação de documentos que irão compor a base de dados do BIEV tanto na forma de posto-fixo-de-consulta quanto no site www.estacaoportoalegre.ufrgs.br, os seus pesquisadores investiram não apenas numa reflexão sobre o sistema de manejo e administração dos fragmentos de tais obras para seu registro em ambas as bases de dados, mas também no sentido do programa de computador de ambos comportar a possibilidade de resgate, por parte do seu usuário, das referencias das fontes dos fragmentos das obras que configuram o seu arranjo documental, além de prever no sistema de cadastramento do BIEV-data a possibilidade de não inclusão de determinados documentos considerados problemáticos para divulgação no site do BIEV.

Nas formas de tratamento documental no interior do BIEV, a discussão acerca do direito que a comunidade urbana portoalegrense tem de aceder ao conhecimento de sua memória coletiva vem associado a reflexões pontuais sobre o tema dos direitos de autor e dos direitos de personalidade como algo que acompanha a rotina de compilação de dados etnográficos no âmbito da pesquisa antropológica no mundo urbano contemporâneo.

Ressalta-se dentre muitas reflexões aquela sobre o processo de organização de dados etnográficos, a partir de sua numerização (a digitalização, com a redução do dado a um código numérico binário), como forma seu registro documental, de um lado, e as formas de seu resgate, em termos da dinâmica de sua re-apresentação, na forma virtual, na tela de um computador. A produção de novas escritas etnográficas com base no contexto enunciativo que constituem as novas textualidades eletrônicas tem provocado entre os pesquisadores do BIEV uma reflexão cada vez maior em torno do processo de desterritoralização da representação etnográfica e a desmaterialização do texto etnográfico. Os dados etnográficos ao serem disponibilizados em ambientes como as redes mundiais de computadores, passam a serem acessados através de formas diversas de sequiências associativas com base em relações não lineares entre seus componentes.

Pelas características do ambiente $W E B$, a produção de uma obra etnográfica para a Internet cria a deslinearização do discurso narrativo autoral ao mesmo tempo em que permite sua relinearização a partir de um leitor singular. Isto porque nas textualidades eletrônicas, a leitura das informações e dados contidos num conjunto documental se modifica a cada ação do leitornavegador, e onde cada ação interpretativa implica atos de manipulação, sempre parcial, e até certo ponto aleatória, de conjuntos de documentos, onde um determinado trajeto de resgate de dados etnográficos acaba por modificar a sua ação interpretativa anterior, obrigando o leitornavegador retroagir com ela, num processo de desconstrução que pode representar para muitos 
antropólogos, hoje, uma ameaça para a objetividade de seu conteúdo tanto quanto à diluição do próprio dado etnográfico, pela modificação na sua natureza de origem.

De acordo com as finalidades didático-científicas de divulgação dos dados das pesquisas que se desenvolvem no Banco de Imagens e Efeitos Visuais, os documentos visuais e sonoros que configuram as coleções etnografias disponíveis tanto no BIEV-site quanto do BIEV-data, assumem, no seu interior, um caráter de citação. Desta forma, os documentos etnográficos que configuram as duas bases de dados do BIEV adquirirem o estatuto de notas e referências cruzadas, recolhidas de inúmeras obras, num procedimento em que os conteúdos destes documentos tendem a se individualizar de suas fontes de origem, provocando um problema em termos da objetividade documental. Ou seja, na pesquisa do BIEV, o uso das novas tecnologias aplicado aos estudos de memória e patrimônio no mundo contemporâneo, resulta no estudo dos arranjos entre as formas clássicas de produção de escritas etnográficas e a modelização discursiva de um programa de informática, sem excluí-las da historia de tais formas discursivas.

Não se trata, assim, de criticar a deslinearização da narrativa etnográfica diante do caráter descentralizado das redes mundiais de computadores, mas potencializar o uso destas tecnologias no tratamento documental da memória, com base na construção de sistemas hipertextos, explorando-se o fato da narrativa etnográfica, neste ambiente, se produzir a partir de sistemas abertos, baseados nos conceitos de bifurcação e não-linearidade de acesso a documentos, dados e informações; e onde a ordem de conhecimento antropológico poderia ser sempre reversível por apoiar-se precisamente numa textualidade até certo ponto incompleta e desordenada ${ }^{4}$.

O procedimento de transformar o documento etnográfico, de seu suporte original (em sua forma analógica, fixa e até certo ponto perene) para dado numérico conduz muitas vezes ao pesquisador desavisado ao sentimento de assistir à ruína da integridade, da identidade e da autenticidade do documento etnográfico. Obviamente, este não é ponto de vista adotado na pesquisa do BIEV com coleções etnográficas e nos seus desafios da criação de um museu virtual da cidade de Porto Alegre. Ao invés de se pensar a representação etnográfica no interior das redes eletrônicas e digitais segundo a perspectiva clássica de sua referência aos fatos do mundo social, ao qual antropólogo deve se ajustar e/ou confrontar, os documentos que são apresentados nas coleções etnográficas digitais do BIEV, no site www.estacaoportoalegre.com.br ou no pontofixo-de-consulta (BIEV-data), exploram precisamente as modificações que percursos propostos

\footnotetext{
${ }^{4}$ Numa escrita de etnografia hipertextual, os documentos originalmente registrados pelo antropólogo em campo a partir de suportes materiais (papel, película, etc.) tem sua representação, primeiramente, decodificada sob uma forma binária de informação para, logo após, em função dos seus contextos de consulta, passarem a se apresentar sob a forma semiótica, legível, resultado dos cálculos do próprio computador.
} 
pelo usuário em sua consulta a tais base de dados lhe provocam pelo fato de permitir a ele múltiplas leituras de um mesmo conjunto documental. $\mathrm{O}$ interesse da pesquisa com os jogos da memória eletrônica e das novas textualidades que ela inventa reside justamente no ato de se explorar esta circunstância que faz com que o leitor-navegador, diante de múltiplas telas-janelas dispostas segundo laços interconectados por uma configuração virtual, não observe uma relação direta dos dados etnográficos com o mundo real dos fatos observados em campo pelo próprio antropólogo e de onde eles se originaram. ${ }^{5}$

\section{A reversibilidade como condição do contexto enunciativo na $W E B$}

No caso da construção de um site contendo coleções de imagens de natureza diversas (texto, fotografia, filme e som) originadas nas pesquisas etnográficas realizadas no BIEV sobre a memória coletiva, os itinerários dos grupos urbanos e o patrimônio etnológico da comunidade portoalegrense, e disponibilizadas num mesmo ambiente de consulta, não se pode prescindir de uma reflexão em torno dos direitos autorais e dos direitos de personalidade que desfrutam tais imagens, muito menos de um estudo mais minucioso acerca da crise da representação etnográfica no contexto enunciativo da Internet face ao contexto clássico do objeto-livro.

Ao se aceitar a afirmação segundo a qual a emergência do termo hipertexto nas ciências sociais é recente tanto quanto o termo complexidade, e que a primeira noção operacionaliza a segunda, então, pode-se supor que a possibilidade de produção de etnografias hipertextuais tem por base a construção, no plano dos estilos da escrita antropológica, de uma retórica mais aberta, fluída e dinâmica de se "recuperar' os dados de campos tanto quanto de ampliar as "propriedades" e "proposições" da produção de conhecimento em Antropologia ${ }^{6}$. Os conceitos de complexidade e intertextualidade são, portanto, conceitos fundamentais para se operar com a produção da escrita etnográfica em hipertextos como forma de divulgação do resultado de estudos antropológicos em websites, implicando a construção de uma escrita etnográfica mais aberta e mais dinâmica, pelo fato da sua leitura se converter, para o usuário da Internet, numa ação de busca onde o leitor-navegador não consegue jamais ver globalmente todo conjunto de dados documentais, tendo dele apenas uma visão local ${ }^{7}$.

\footnotetext{
${ }^{5}$ Em referência a outro artigo já publicado no site www.estacaoportoalegre.com.br, denomina-se aqui de hipertexto etnográfico, um conjunto não estruturado a priori de informações e dados registrados pelo antropólogo em seu trabalho de campo, em suporte diversos (textos, fotos, sons, filmes, etc.) que, digitalizados, são colocados num mesmo ambiente de consulta e que, ligados entre si, conformam sua interpretação de determinada culturas, segundo um sistema aberto e onde a ação de leitura de um dado etnográfico imediatamente re-configura a totalidade dos conhecimentos ali reunidos.

${ }^{6}$ A propósito destas noções aqui empregadas ver C. GEERTZ Obras e vidas. O antropólogo como autor.Rio de Janeiro, Editora UFRJ, 2003.

${ }^{7}$ Cf. J. CLÉMENT, Hypertexte et complexité, publicado na Revue Études Françaises, março de 2000, Presse de 1'Université de Montreal, Vol 36, No 2.
} 
Quando os escritos dos antropólogos ultrapassam os meios de veiculação que as Ciências Sociais dispunham, até então, para divulgar suas formas de conhecimento - os artigos em revistas especializadas, os livros que circulam "nas escrivaninhas das bibliotecas do campus", 8 as exposições fotográficas, as mostras de documentários, etc. - as convenções literárias que cercam as operações textuais nas quais esta mergulhada a produção da obra etnográfica, e na qual se origina a construção da autoridade do antropólogo, extrapolam as micro-práticas acadêmicas, e acabam por tencioná-las do seu próprio o interior.

Esta nova forma de organização dos saberes que se dá a partir de sua numerização, e sua disponibilização na rede mundial de computadores, modifica o estatuto do texto etnográfico separando-o do seu suporte original, o livro. Da mesma forma, rompe-se com a idéia de que todo o conhecimento etnográfico deve ser obtido através da sua referência aos elementos constituintes de um sistema cultural. No ambiente das redes eletrônicas e digitais, o texto etnográfico se desmaterializa, se torna objeto instável, modificável e transferível configurando-se a partir da rede de conexões de dados e informações complexas, sendo este um espaço privilegiado do ato interpretativo das culturas. Uma tal produção desafia a idéia clássica do conhecimento como um sistema regido pelo principio de ordem, uma vez que na Internet, por exemplo, esta ordem é sempre reversível por ser sistema incompleto e, até certo, ponto desordenado.

Mas, se a grande liberdade de expressão é um dos méritos do ambiente WEB, a manutenção deste requisito exige mecanismos capazes de assegurar uma reflexão em torno dos laços hipertextos do qual resulta a obra etnográfica na Internet. ${ }^{9}$ No debate sobre esta matéria da construção de etnografias hipertextuais, indivíduo, política e moralidade, as três categorias modernas de interpretação do oficio do antropólogo no mundo contemporâneo ${ }^{10}$, aparecem aqui entrelaçadas ao questionar os dispositivos de poder que presidem os contextos enunciativos clássicos do saber antropológico.

No Banco de Imagens e Efeitos Visuais, seja no caso do posto-fixo-de-consulta, seja do

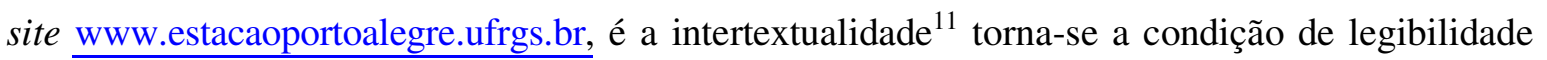
da autoridade etnográfica do antropólogo em sua escrita hipertextual. Isto porque a textualidade eletrônica coloca o antropólogo-autor diante do desafio da responder pelos laços hipertextos internos, automáticos e profundos (que estão fora do âmbito da decisão do usuário-internauta e que são da responsabilidade tanto do programador quanto do antropólogo, se as duas funções não

\footnotetext{
${ }^{8}$ Cf. expressão empregada por P. RABINOW, Antropologia da razão. Rio de Janeiro, Relume-Dumara, 1999, p. 84

${ }^{9} \mathrm{Na}$ criação de novas escritas etnográficas em hipertexto, por exemplo, há todo um extenso trabalho de definição da natureza dos laços entre os dados e informações disponibilizados, bem como de precisão do conteúdo dos "nós" que os unem entre si e da estrutura de percursos para posterior utilização do leitor, procedimentos que não poderão ser abordados aqui, mas que encontram-se disponíveis na publicação eletrônica Iluminuras, no site www.estacaoportoalegre.ufrgs.br.

${ }^{10}$ Cf. CARDOSO DE OLIVEIRA, R. \& CARDOSO DE OLIVEIRA, L. R. Ensaios antropológicos sobre moral e ética.

Biblioteca Tempo Universitário 99. Rio de Janeiro, Tempo Brasileiro, 1996.
} 
estiverem subsumidas numa mesma pessoa), através dos quais os documentos de uma mesma coleção são colocados num mesmo ambiente de consulta, tanto quanto pelos laços hipertextuais externos, ativáveis e simples, os quais são acionados pelo usuário da Internet, obtendo com isto sua co-responsabilidade com o dado disponibilizado na rede mundial de computadores. ${ }^{12}$

Diante das novas textualidades digitais e eletrônicas, e fora do espaço livresco e acadêmico clássico onde as obras dos antropólogos costumam circular, a duvida autoral e a insegurança moral e epistemológica que costuma habitar o estatuto da representação etnográfica na pesquisa antropológica, ampliam-se mais ainda. A produção antropológica disponibilizada no ambiente $W E B$, ao se apoiar num sistema de intercomunicação completamente diferente daquele dos livros, das teses, dos vídeos e filmes, das exposições fotográficas, etc., amplia, em proporções inusitadas, em relação a tais tecnologias oriundas da invenção da imprensa, da fotografia e do cinema, o debate em torno dos direitos de personalidade e dos direitos autorais.

Ao se ter em mente o uso da imagem na produção de escritas etnográficas para $W E B$, os trabalhos de produção, criação e geração de coleções etnográficas no Banco de Imagens e Efeitos tem tornado evidente para os seus pesquisadores e bolsistas que os direitos de personalidade e os direitos de autor, apresentam aspectos de ordens distintas. O primeiro deles tem uma base constitucional, referindo-se a inviolabilidade do direito de qualquer pessoa à sua imagem ${ }^{13}$, sendo tratado no plano do direito constitucional; o segundo protege o direito das pessoas no que se refere à propriedade das obras por ela produzidas, e disto decorrem questões patrimoniais tendo em vista que a integridade da obra passa pelo usufruto dos benefícios desta autoria. Diante desta problemática, no respeito aos direitos de personalidade (de imagem e som) e dos direitos autorais e direitos conexos, os pesquisadores e bolsistas do BIEV baseiam suas ações de conservação, produção, geração e criação de documentos-imagens da cidade de Porto Alegre na aceitação prévia de alguns pressupostos que lhe garantem uma legitimidade no campo de atuação ao qual ele se destina.

Por um lado, em se tratando de reproduções, na forma digital, de imagens da cidade de Porto Alegre (pinturas, gravuras, desenhos, aquarelas, etc. além de outros materiais gráficos) retiradas de publicações impressas, tais imagens aparecem na condição de citação, com referência explicita ao seu autor e a obra de onde foram retiradas. Aliás, vale ressaltar que toda e qualquer imagem selecionada para constar na base de dados do BIEV, tem como obrigatório uma referência às suas fontes, utilizando-se os requisitos comuns para a apresentação de bibliografia.

\footnotetext{
${ }^{11}$ Sobre o tema da intertextualidade ver RIFATERRE, M. La production du texte. Paris, Seuil, 1979.

${ }^{12}$ A propósito dos laços e nós na construção do hipertexto ver CLEMENT, Jean. Hypertexte et fiction : la question du lien. http://www.interdisciplines.org/defispublicationweb, site consultado em março de 2004.

${ }^{13}$ Ver a respeito o artigo $5^{\circ}$, inciso X da Constituição Federal de 1988.
} 
Este é também o caso dos extratos de crônicas e reportagens, de depoimentos e relatos, de poesias e de romances que tem Porto Alegre como cenário são objetos de estudo e pesquisa no $\mathrm{BIEV}$, sendo permitida apenas a reprodução de pequenos trechos, de qualquer natureza, mas nunca a obra integral. Na seleção de fotos noticias e de partes de reportagens a orientação que se tem adotado no cadastro de coleções etnográficas é dar prioridade às fotos emblemáticas, adotando o mesmo procedimento para noticias e reportagens onde elas se encontram situadas.

Por outro lado, no que se refere ao tema do direito de personalidade, as imagens capturadas e produzidas no trabalho de campo por pesquisadores e bolsistas, tais como esculturas e estatuárias, ornamentos, etc, e que conformam a paisagem urbana da cidade, ainda que estas não precisem autorização por encontrar-se em espaços públicos, estão sempre referidas aos lugares onde foram colocadas à disposição de seus habitantes, sendo seu autor, ele próprio, responsável por formar sua coleção etnográfica, disponibilizando-a na base de dados do BIEV, nisto envolvendo sua autorização para o uso de suas imagens.

No que tange ao registro de imagens de pessoas no espaço público da cidade de Porto Alegre, tanto na produção audiovisual dos pesquisadores e dos bolsistas do BIEV quanto no resgate de imagens antigas da cidade, tem-se por critério o fato de que tais imagens têm por definição o seu caráter público, podendo ser usadas na formação das coleções, mas sem qualquer autorização para fins comerciais ou de propaganda, ainda que tenha a autorização daquele que fez o registro. Em se tratando de produção de imagens que não pertença aos bolsistas e pesquisadores do BIEV, para constar no seu acervo digital, os documentos tratam de reproduções, usados na condição de citação, e que tem como obrigatório, quando de seu cadastro na base de dados, a referência às suas fontes. Como procedimento, pesquisadores e bolsistas ao serem contatos para a obtenção destas ultimas imagens sugere-se que o interessado seja encaminhado aos locais que possuem a guarda dos originais e com os quais podem obter informações sobre sua autorização de uso, tanto direito autoral quanto, se for o caso, de direito de personalidade, uma vez que em muitos casos, seu uso envolve questões financeiras.

\section{O caso das coleções etnográficas reunidas no Banco de Imagens e Efeitos Visuais}

Conforme apontam alguns antropólogos é quando reconhecemos que o conhecimento está aliado a uma ação concreta no mundo social que o próprio conhecimento científico torna-se alvo de reflexão e de intenções políticas. Neste quadro é que se insere o BIEV com o seu trabalho voltado ao resgate e divulgação dos dados de pesquisas etnográfica na e da cidade de Porto Alegre, valendo-se das novas tecnologias digitais e eletrônicas como formas de registro/resgate/produção e criação de seu patrimônio etnológico. Os trabalhos de configuração 
das bases de dados do BIEV-data tanto quanto do BIEV-site têm possibilitado uma reflexão sobre os limites que as novas tecnologias impõem ao fazer antropológico no sentido das exigências de se explicitar $\mathrm{o}$ ato interpretativo que comporta todo o registro de dados etnográficos bem como as retóricas empregadas pelo antropólogo para re-configurar o sentido deste material no interior de uma narrativa etnográfica hipertextual. Em especial, o Banco de Imagens e Efeitos Visuais, por se tratar de um banco de dados digitais sobre memória coletiva e estética urbana em Porto Alegre, na forma de um museu virtual, acessível na Internet, na forma de compilações de dados e informações obtidos junto a museus e arquivos históricos locais ou delegadas ao BIEV por particulares, para sua reprodução digital, ou de dados etnográficos contendo descrições de imagens visuais e sonoras capturadas por seus pesquisadores antropólogos em suas pesquisa na cidade, tem se exposto às exigências de uma renovação do que denominou as "energias discursivas da antropologia"14 na era das redes eletrônicas e digitais.

Os contextos enunciativos da $W E B$, tendo como filtro de credibilidade dos produtos culturais que veicula os seus próprios usuários à cadeia de relações sociais em que eles se encontram situados, desafia, assim, o sentido do ato de interpretação das culturas do qual se originam as modalidades do pensamento antropológico, considerado ele próprio herdeiro de uma tradição "livresca" e "museográfica" de representação do Outro. Mas se a invenção da escrita assim como da imprensa, conforme sustentam os estudos de autores tão diversos, liberou o conhecimento humano do constrangimento de suas condições espaço-temporais ${ }^{15}$, o comportamento errático dos leitores-navegadores das redes mundiais de computadores atualmente permite a re-contextualização da escrita dos conteúdos culturais dentro de um novo campo semântico.

Para o caso das coleções etnográficas disponibilizados pelo Banco de Imagens e Efeitos Visuais, acima de tudo na forma de site, ao invés de se negar um tal comportamento errático, interessa conduzir o usuário-internauta a explorar tal comportamento no contato com suas coleções etnográficas compostas de imagens antigas da cidade de Porto Alegre, retiradas, como fragmentos, de obras literárias, de produções audiovisuais, de álbuns fotográficos, de jornais, de revistas, etc. tanto quanto de imagens recentes, produzidas por seus pesquisadores e bolsistas, todas elas, evidentemente comportando vários elementos que são suscetíveis de serem protegidos mediante os direitos de personalidade e os direitos de autor. Neste sentido, a grande finalidade do BIEV-site tem sido o de incrementar a difusão da cultura urbana portoalegrense através da

\footnotetext{
${ }^{14}$ Cf expressão de C. GEERTZ EM Obras e vidas. O antropólogo como autor.Rio de Janeiro, Editora UFRJ, 2002, p. 181.

15 A propósito ver LEROI-GOUHRAN, André. Le geste et la parole, Paris, Albain Michel, 1969, GOODY, Jack. La raison graphique: la domestication de la pensée sauvage. Paris, Minuit, 1979, E. A. HAVELOCK A revolução da escrita na Grécia e suas conseqüências culturais, São Paulo: EDUNESP, Rio de Janeiro, Paz e Terra, 1996 e DERRIDA, Jacques De la grammatologie, Paris, Minuit, 1967, entre outros.
} 
divulgação do acervo de imagens que configuram o patrimônio etnológico da comunidade urbana portoalegrense, contemplando como público alvo os seus habitantes locais, dos anônimos aos notáveis; dos artistas, aos pensadores, aos cientistas passando por um público simplesmente amante desta cidade, sem com isto ferir o usufruto do direito autoral de sua criação.

Neste ponto, para existir em sua forma de museu virtual, as coleções etnográficas que configuram a base de dados do BIEV, nas formas posto-fixo-de-consulta (BIEV-data) ou na $W E B$ (www.estacaoportoalegre.ufrgs.br), pode se valer da proteção do art. $7^{\circ}$, inciso XIII, da Lei 9.610/98, que coloca a "base de dados" no rol das obras legalmente protegidas. Tais coleções etnográficas, ao integrarem uma base de dados, nos moldes de um sistema organizado, dotado de identidade própria, poderiam situar-se no rol de obras como as compilações, coletâneas ou as enciclopédias as quais, por sua seleção, organização ou disposição de conteúdo, constituem uma criação intelectual. Disponibilizando suas coleções etnográficas na rede mundial de computadores, no âmbito de uma coletânea de documentos relacionados à memória coletiva e estética urbana da cidade de Porto Alegre, ainda que pertencendo isoladamente a terceiros - seus criadores originais-, a base de dados do BIEV também resulta da produção autoral dos pesquisadores que nele atuam, não como criadores das obras em si, mas da obra conjunta, organizada, direcionada à difusão de conhecimentos da cultura urbana local, que pensamos, não pode, nem deve ser privilégio ou monopólio de ninguém.

Evidentemente, esta proteção autoral a base de dados do BIEV não atinge os documentos que dela fazem parte em sua forma nativa (analógica). A veiculação das coleções do BIEV na $W E B$ tem por fundamento a defesa do argumento de que um tal banco de dados trata de informações e documentos de utilidade pública, e que sua divulgação/difusão na rede mundial de computadores busca cumprir um direito constitucionalmente garantido a qualquer pessoa, principalmente por todos aqueles se interessam pelos temas de memória e patrimônio no mundo urbano contemporâneo, não podendo ser propriedade de ninguém em particular. Atuando segundo este princípio o BIEV adota uma baixa resolução para todas as imagens que configuram a suas coleções disponíveis na rede mundial de computadores.

Segundo se postula nos trabalhos do Banco de Imagens e Efeitos Visuais, parte da riqueza da retórica hipertextual, diferente da retórica da operação textual da qual resulta o objetolivro ou objeto-vídeo, por exemplo, reside na sua característica intrínseca que é a de "desterritorializar" toda e qualquer representação, reduzindo-a a um código numérico binário. ${ }^{16}$

\footnotetext{
${ }^{16}$ Jean Clement "Du texte à l'hypertexte: vers une épistémologie de la discursivité hypertextuelle" in Hypertextes et hypermédias: Réalisations, Outils, Méthodes, Hermès, 1995.
} 
Esta característica da memória eletrônica e digital faz com que a antiga disjunção do sujeito do conhecimento (res cogitans) e da coisa pensada (res extensa) seja superada, pois com as novas tecnologias ambos encontram-se reunidos numa unidade ${ }^{17}$.

Diferente de ler um livro, a leitura de uma etnografia em hipertexto se converte numa ação de busca onde o leitor-navegador não consegue jamais ver globalmente todo o conjunto de dados documentais, tendo dele apenas uma visão local. Neste ponto, consideramos que o uso das novas tecnologias digitais e eletrônicas na pesquisa antropológica assim como a divulgação de estudos etnográficos em website nas redes mundiais de computadores, pela ambigüidade característica da representação digital e eletrônica nos provoca a pensar o processo de leitura e escrita da representação etnográfica clássica em termos de sua natureza e forma.

Além disto, migração de toda e qualquer imagem que consta no BIEV-data (posto-fixo-

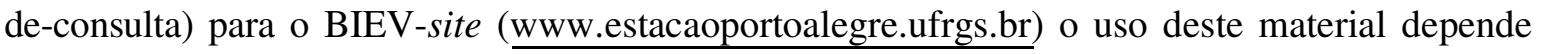
de uma seleção prévia por parte do pesquisador e do bolsista do que pode ou não ser veiculado na rede mundial de computadores, sempre com a preocupação de preservar a memória do autor no sentido da qualificação de sua criação junto a comunidade urbana portoalegrense. Isto posto, a construção de novos experimentos etnográficos tendo como suporte as redes digitais e eletrônicas, ao dispor os dados e informações, organizados na forma de uma rede e dentro de um formato de textualidade não linear, segundo seus múltiplos acessos ${ }^{18}$, traz à luz outras reflexões interessantes para o próprio fazer antropológico no mundo contemporâneo.

\section{A produção de conhecimento em Antropologia sob a tutela dos direitos autorais e os direitos de imagem e som}

Hoje, mais do que nunca, as imagens digitalizadas podem ser distribuídas com pouco esforço para milhões de computadores ao redor do mundo e se tornar acessível a milhões de pessoas, sendo que qualquer um pode se apropriar delas, no todo ou em parte, e a submetê-las à manipulação até esta imagem não ser mais reconhecida. No mundo contemporâneo, na sequiência da criação de mecanismos eletrônicos de reprodução de imagens, tais como o xerox e o scanner, e na esteira da introdução do sistema numérico e da comunicação por satélites, nunca foi tão fácil e irreprimível o apossamento de imagens como tem sido na Internet.

\footnotetext{
17 A respeito ver Kevin Taylor ANDERSON, Etnographic hypermedia- transcending thick descriptions, 1999. http://cc.joensuu.fi/sights/kevin.htm, site consultado em janeiro de 2004.

${ }^{18}$ Cf. comentários de Jean. CLEMENT, "Hypertexte et fiction, une affaire de liens", in Salaün, J.-M. et Vandendorpe, C. Les défis de la publication sur le web: hyperlectures, cybertextes et meta-éditions, Presses de l'ENSSIB, 2004.
} 
Mesmo nos sites que apresentam enunciados que alertam para os limites de uso sobre as imagens que eles veiculam, fica evidente que não há trancas ou mecanismos que proíbam totalmente o usuário-internauta da WEB de apossar-se de tais imagens. Basta dar um click no botão direito do mouse e acionar a opção "save image as" numa caixa de diálogo que surge de imediato no monitor e, em frações de segundos, a imagem é copiada do site pesquisado para o diretório do navegador. É exatamente em razão desta forma frágil com que se apresenta o contexto enunciativo na Internet que o tema da ética vinculado à autoria e ao direito de uso da imagem no ambiente da rede mundial de computadores aparece com maior força.

Distanciando-se, apenas aparentemente, do debate dos direitos autorais e dos direitos de personalidade, no que se refere a produção de novas escritas etnográficas dirigidas a rede mundial de computadores, seria importante se ampliar, nesta parte deste artigo, o assunto à luz de uma reflexão, ainda que breve, dos laços que unem o nascimento de toda e qualquer produção de conhecimento em Antropologia às trocas sociais nas quais semelhante obra se origina. $\mathrm{O}$ que implicaria recolocar o tema do direito de paternidade de uma obra assim como dos direitos de personalidade sob a imagem ou voz daquele que nela é retratado sob outra perspectiva das situações onde se originam. A tentativa é deslocar o debate acerca da doutrina jurídica que rege a aplicação de ambas as leis referidas ao direito de propriedade intelectual e aos direitos fundamentais da pessoa, decorrentes da própria condição humana (imagem, voz, nome, honra) para poder, desde a matriz antropológica, contribuir para a sua ampliação.

Sob este ângulo, reconhece-se que o BIEV enquadra suas ações em procedimentos de armazenamento, em suporte digital e eletrônico, não de obras, mas de fragmentos e passagens destas obras compiladas na forma de uma base de dados, o que não ausenta o trabalho de produção "textual” de seus pesquisadores, ao operar com imagens a partir de seus mais variados suportes, de estar sujeito às leis de direitos autorais e de direitos de personalidade. Desta forma, e diante dos desafios de restauração da palavra do Outro, a produção de etnografias na forma de hipertextos no âmbito do Banco de Imagens e Efeitos Visuais tem conduzido seus pesquisadores a conviver com o desafio de superar os limites do dilema dos princípios éticos que orientam o saber-fazer antropológico, tradicionalmente produzido na forma de objeto-livro quando este é confrontado, na era das textualidades eletrônicas, aos desafios de se romper um discurso hegemônico sobre o Outro no exercício de projetar os resultados de sua pesquisa na rede mundial de computadores.

Por se tratar de bancos de dados que opera com coleções etnográficas criadas e produzidas a partir de fragmentos digitalizados de obras da cultura urbana portoalegrense, e constituída como um conjunto de conteúdos da natureza variada tendo uma coerência entre eles, 
gerenciados por uma mesma entidade (ftp, site) e relacionados entre si na modalidade de um hipertexto, através de interfaces criadas especialmente para esta finalidade, o BIEV se pretende enquadrar dentro do Art. 49, desta Lei que afirma não constituir ofensa aos direitos do autor à reprodução de trechos de obras já publicadas, ou ainda que integral, de pequenas composições alheias no contexto de obra maior, desde que esta apresente caráter CIENTÍFICO, DIDÁTICO $O U$ religioso, e haja a indicação da origem e o autor. Assim, a tutela do direito autoral, no caso das coleções etnográficas do BIEV sofreria "derrogações à vista do interesse público" de divulgação de imagens visuais e sonoras, sem fins lucrativos de qualquer sorte, que configuram o patrimônio etnológico da comunidade urbana portoalegrense.

Sob a ótica da legislação de direitos autorais e dos direitos de personalidade, toda e qualquer montagem explorando imagens de pessoas públicas, todas as charges e caricaturas de cidadãos públicos, todos as apropriações de imagens de objetos, retiradas de suas funções originais seriam, em princípio, consideradas uma adaptação de uma criação original, na qual caberia tanto aquele que é retrato quanto ao autor da imagem original conceder os direitos de seu uso.Observa-se ai um paliativo para se recompor a totalidade de sentido que antes reunia o autor, sujeito humano, à sua obra. Subtraído de sua própria criação, ameaçado de suprema alienação, na atual civilização da imagem, todo o autor, para ser usufruir os benefícios de sua obra, corre o risco de ser equiparado a ela, e isto, muitas vezes de forma unilateral e unidimensional. Segundo Carlos Heitor Cony ${ }^{19}$ este quadro de disputas em torno da legitimidade quanto ao direito de imagem" na Internet, nascido na Constituição de 88, precisa ser disciplinado de "forma sensata" pois, tendo sido interpretado "aleatoriamente" pelo Judiciário, tem muitas vezes se tornado "uma ameaça que pode ser usada por qualquer um contra qualquer um".

Interessante se observar que os direitos autorais e os direitos de personalidade que protegem obras como as produções audiovisuais tanto aquelas destinadas a $W E B$ quanto a outro contexto enunciativo, decorrem da preocupação com a assinatura que tais objetos culturais trazem, seja de um autor determinado no sentido de expressarem o resultado material das idéias e dos métodos do qual ele se vale para criá-los, seja de uma cultura na defesa do direito a imagem daquilo ou daquele que se encontra por eles re-presentado. Alguns juristas reconhecem, inclusive, que a defesa dos direitos autorais ganha mais importância quando os objetos culturais sujeitos as leis de direitos autorais e/ou leis de personalidade adquirem uma expressão em base corpórea, concreta, palpável, não abarcando qualquer idéia ou conceito existente por detrás de uma obra criada.

\footnotetext{
${ }^{19}$ Cf. Cornelia. Eckert et alli Olhares cruzados, olhares legítimos? Antropologia em Perspectivas,V Reunião de Antropologia do Mercosul, Florianópolis, 30 novembro a 03 de dezembro de 2003, Grupo de trabalho: Antropologia e Imagem: entre debates políticos, éticos, estéticos e interpretativos, Coordenação: Suzana Sel (UBA-Arg.) e Liliane Guterres (UFRGS).
} 
Diante disto, no plano das obras da cultura humana que conformam as criações imateriais, poder-se-ia reivindicar, por assim dizer, o predomínio da não tutela dos direitos autorais e dos direitos de personalidade. Nesta situação, poder-se-ia pensar a ausência da representação da figura jurídica do autor tendo em vista que tais criações não possuem as dimensões morais e patrimoniais associadas a uma tal figura, por não se tratar da criação de um indivíduo, o titular da obra, mas de coletividades, de grupos sociais, de etnias, das quais dependeria a autorização dos usos comerciais e pecuniários de tais bens. Tais obras, cujas formas intangíveis alimentam o mundo dos objetos (lendas e mitos, cantos e contos, etc.), e com as quais os antropólogos constantemente travam contato, e cujas pistas e vestígios no mundo social buscam freqüentemente capturar, em suas pesquisas de campo, não se constituem como obras de domínio público, muito embora talvez pudesse o ser, ainda que isto as tornasse, por ironia, imunes ao direito autoral.

No BIEV a construção de novos experimentos etnográficos tendo como suporte as redes digitais e eletrônicas, ao dispor os dados e informações, organizados na forma de uma rede e dentro de um formato de textualidade não linear, segundo seus múltiplos acessos, traz à luz outras reflexões interessantes para o próprio fazer antropológico no mundo contemporâneo. Uma destas reflexões pode ser traduzida na seguinte indagação: quais transformações se operam na escrita etnográfica quando a produção dos antropólogos não mais se destina à sua difusão restrita a sua comunidade lingüística, mas se dirige a rede mundial de computadores, e onde a restituição da fala e da imagem do outro é dependente da forma como o leitor-navegador opera, na tela do computador, a leitura deste documento? Como assegurar, num tal ambiente que provoca a desordem e rompimento com a natureza do direito autoral relacionado às práticas culturais de leitura e escrita do objeto-livro, a inviolabilidade do direito autoral ou do direito de imagem e som?

Nas ultimas décadas muito se discutiu sobre a "empreitada etnográfica" e as questões epistemológicas que cercam o fazer antropológico e os seus padrões de argumentação. Uma abordagem, entretanto, que tem se limitado a discutir os dilemas que cercam a prática da escrita do autor-antropólogo em termos dos desafios da produção textual. Entretanto, pouco se pode ler acerca desta controversa quando o tema em pauta é o debate do estatuto da representação etnográfica a partir das repercussões que a difusão da produção antropológica provoca para além de sua comunidade de leitores de origem, principalmente quando ela atinge a rede mundial de computadores e se torna cada vez mais sujeita as múltiplas interpretações e apropriações.

Em especial, as pesquisas com novas escritas etnográfica nas redes eletrônicas e digitais no Banco de Imagens e Efeitos Visuais têm sido expostas às exigências de uma renovação das 
"energias discursivas da antropologia" 20 . Neste sentido, o debate em torno dos direitos de personalidade (direitos invioláveis de som e de imagem) e dos direitos autorais que envolvem a produção, criação e geração de escritas etnográficas com base nas novas textualidades eletrônicas deslocam, em 3 aspectos, as formas clássicas do pensamento antropológico herdadas pelos contemporâneos.

Na produção/difusão do conhecimento em Antropologia, estas novas escritas etnográficas deslocam a figura do antropólogo como autor na medida em que sua autoridade etnográfica sobre os abalos da deslinearização da narrativa etnográfica e da fragilização de seu significado autoral, se torna dependente das múltiplas interpretações dos seus leitores. As textualidades eletrônicas, configurando como sistemas abertos, com base nos conceitos de bifurcação e nãolinearidade, ${ }^{21}$ amplificam ao mesmo tempo os problemas do processo de restituição da palavra do outro enfrentados antropólogo no âmbito do espaço livresco e da cultura da escrita.

Em particular, neste ponto, dois aspectos podem ser ressaltados: atualmente, a rede mundial de computadores ocupa cada vez mais um espaço de afirmação da identidade social de grupos e minorias no plano da comunidade internacional tanto quanto de viabilização do repatriamento de bens culturais aos seus locais de origem, pelo grau de interconectividade que ela permite entre os seus usuários-internautas. Além disto, a produção de novas escritas antropológicas na $W E B$ desafiam as bases ético-moral e legal da produção do conhecimento em Antropologia, uma vez que o conjunto de regras que instauram os direitos de propriedade intelectual e de personalidade (de imagem, de som, etc.) não são garantem critérios para estabelecer os limites entre informação e ruído, pois faz parte das praticas enunciativas inerente ao ambiente das redes digitais e eletrônicas a manipulação de dados dos quais o usuáriointernauta leigo desconhece o sistema de origem de onde tais informações provêem.

Com isto se quer apontar que qualquer escrita dirigida as redes mundiais de computadores não pode se apoiar na linearidade das informações que seu autor fornece, como ocorre no espaço livresco onde elas aparecem dispostas uma após a outra, uma vez que tais informações para serem acessada dependem de determinadas ações de consulta realizadas pelo usuário-internauta em um tal ambiente. Finalmente, na civilização da imagem, a produção audiovisual dos antropólogos - e entre elas a produção dirigidas à Internet- adquire cada vez mais interesse para os "empresários da cultura" tornado-se ela própria parte do consumo de uma cultura visual do exótico e do bizarro, um fato que tem desafiado o antropólogo tanto quanto os grupos sociais e coletividades por ele estudado a compreender a prática do seu ofício e a sua

${ }^{20}$ Cf. expressão utilizada por Clifford.GEERTZ, Obras e vidas. O antropólogo como autor.Rio de Janeiro, Editora UFRJ, 2002, p. 181 . 
sobrevivência no interior de complexos processos de globalização e das questões financeiras de mercado de bens culturais deles decorrentes.

Tomando-se em conta os pontos mencionados acima, caberia aqui, em especial, se retomar o debate das imbricações entre os direitos autorais e os direitos de personalidade que estão na base do saber-fazer antropológico, colocando-o no interior da prática etnográfica, de um deontologia do trabalho de campo na Antropologia. Hoje, para um antropólogo, numa situação eventual de uso indevido de sua produção audiovisual reivindicar a defesa e a proteção da integridade da sua obra a partir conceito de autoria a ela vinculada, desde o abalo das fundações morais da autoridade etnográfica pelos pós-modernos, seria algo possível, mas pouco provável. No plano jurídico legal, é mais contundente ao antropólogo reivindicar este direito com base no fato de esta obra expressa uma relação singular dele com seus informantes e que, o uso indevido da obra, fere os termos deste contrato acordado entre eles, não gerando um tal acordo direito a terceiros. A razão disto é que, no plano da produção de toda obra de conhecimento, em Antropologia, os direitos de autor não podem ser dissociados da defesa dos direitos de personalidade, pois os direitos de imagem e som são aqueles que estão associados à inviolabilidade da condição humana. Portanto, o respeito à integridade da obra etnográfica já se coloca, dentro de um quadro deontológico da prática profissional do antropólogo, no interior do próprio do encontro etnográfico e das formas de contrato acordadas entre ele e seu grupo de pesquisa.

\section{Os desafios da construção de uma moralidade na produção do conhecimento antropológico}

No caso das formas de produção de conhecimento em Antropologia, discutir os direitos autorais e os direitos de personalidade (de imagem e som) das produções antropológicas quando estas se dirigem ao contexto enunciativo da $W E B$, traz para a cena do debate jurídico-legal importantes contribuições. Um deles é a constatação de que para que se avance o debate a respeito da integridade de tais obras etnográficas no âmbito das novas textualidades eletrônicas é importante que os próprios antropólogos avancem no estudo da significação representacional com que as informações, os fatos, as situações e os acontecimentos colhidos em campo aparecem na "prosa etnográfica"22 para além do espaço livresco.

Em Antropologia, como na ciência, até onde se pode defender a originalidade de uma produção (escrita, sonora ou visual) referida apenas a autoria do antropólogo, sem mencionar as trocas sociais e as interações nas quais esta obra nasceu? Não seria de se pensar a defesa da

21 A respeito ver Jean CLEMENT, Hypertexte et complexité. http://www.interdisciplines.org/defispublicationweb, site consultado em janeiro de 2004.

${ }^{22}$ Cf. Clifford GEERTZ, Obras e vidas. O antropólogo como autor.Rio de Janeiro, Editora UFRJ, 2002, p.178. 
integridade de obra etnográfica implicada tanto na defesa da integridade das formas de vida dos indivíduos e/ou grupos das quais ela resulta quanto na defesa da integridade do pensamento antropológico diante de outros saberes e fazeres? Da mesma forma que o debate sobre a autoria do antropólogo e a da autoridade etnográfica na produção textual (textos saturados de autor, textos esvaziados de autor), a produção etnográfica destinada a WEB não se afasta do debate do lugar já clássico que tem ocupado o antropólogo no processo de reorganização das relações políticas no mundo pós-colonial.

Do ponto de vista moral, não seria de se pensar que a defesa da integridade de uma produção audiovisual em Antropologia implica a defesa da integridade daqueles ou daquilo do qual ela resulta? Tendo em vista que o direito autoral, na sua forma clássica, toma, na sua esfera moral, a defesa e proteção da integridade de toda a obra a partir conceito de originalidade a ela vinculada pela assinatura de seu autor, no caso das formas atuais de produção de conhecimento em Antropologia, desde o abalo de suas fundações morais, com os pós-modernos, como se poderia reivindicar o direito autoral? E como discutir o tema do direito de imagem e som, em suas injunções ou não com o direito autoral, no plano da produção de conhecimento audiovisual em Antropologia? O que pensar das injunções entre o direito autoral e o direito de imagem e som quando se tem presente que a obra etnográfica está à mercê da qualidade ético-moral do encontro etnográfico e das formas de contrato que regem o diálogo cultural entre o antropólogo e seu grupo de pesquisa? Do ponto de vista da produção de conhecimento em Antropologia, quem seria o autor de uma obra etnográfica? Discutir o direito moral associado à obra etnográfica, neste caso poderia despertar a nostalgia da figura do autor na figura do antropólogo na defesa de seus direitos morais, além de patrimonial.

Nesta medida, não convém esquecermos que se a cultura da escrita, desde a Antiguidade, e com a invenção da imprensa chegando à revolução eletrônica, tem avançado sobre o tema do privilégio e das proteções que instauram o direito autoral, não é menos verdade que tais avanços são igualmente acompanhados de atos de sua censura e interdição ${ }^{23}$. Diante das abordagens catastróficas e pessimistas sobre os usos e abusos da pirataria na Internet não se pode deixar de pensar igualmente no que M. FOUCAULT ${ }^{24}$ denominou a "apropriação penal" dos discursos

\footnotetext{
${ }^{23}$ A respeito consultar a obra de Roger CHARTIER A aventura do livro, do leitor a navegador, São Paulo, EDUSP, $1999 \mathrm{e}$ Jean CLEMENT, "Du livre au texte: les implications intellectuelles de l'édition électronique". Sciences et techniques éducatives. Volume 5 - nº 4 , Hermès, 1998.

${ }^{24}$ Ver a respeito o famoso artigo de Michel FOUCAULT, Qu'est-ce qu'un auteur ? , escrito em 1969 e publicado na antologia de A. Brunn, L'Auteur, Paris, GF-Corpus, 2001, texte VI, p. 76-82, onde este autor conclui, na pg 82:" La fonction-auteur est liée au système juridique et institutionnel qui enserre, détermine, articule l'univers des discours; elle ne s'exerce pas uniformément et de la même façon sur tous les discours, à toutes les époques et dans toutes les formes de civilisation; elle n'est pas définie par l'attribution spontanée d'un discours à son producteur, mais par une série d'opérations spécifiques et complexes; elle ne renvoie pas purement et simplement à un individu réel, elle peut donner lieu simultanément à plusieurs ego, à plusieurs positions-sujets que des classes différents d'individus peuvent venir occuper. "
} 
para se pensar a perseguição e a condenação de determinados contextos enunciativos, como pode ser o caso das redes mundiais de computadores, considerados por outros (como aqueles oriundos do espaço livresco) como transgressores.

Novamente retomam-se aqui os estudos dos historiadores da cultura para se situar o atual debate dos direitos autorais na Internet no interior de uma determinada filiação. Trata-se aqui do nascimento da "função do autor" e do espaço livresco tal qual ele se apresenta hoje, o qual sempre foi marcado, desde seus primórdios, pela censura, por um lado, e liberdade de expressão, de outro. ${ }^{25}$ Nesta linha, a atual controversa sobre os direitos de imagem e som e direitos autorais remontaria, assim, ao surgimento da figura do autor e que tem se desenrolado, desde suas origens, no sex XVII, sempre acompanhada de uma "lituânia de processos" em torno da autoria. Portanto, ainda que aqui, hoje, se esteja falando de proteção aos direitos de imagem e som ou se direitos autorais, no fundo, mas também na superfície, o que esta em pauta é cultura da escrita e de todos os seus cânones jurídico-legais.

Distante das ações e gestos que fundaram os procedimentos clássicos de pesquisa em Antropologia, na rede mundial de computadores oferece como território de múltiplas reescrituras, e em razão da desmaterialização/descorporalização do espaço livresco, a qualidade do ato etnográfico tende a ser questionada a partir do debate sobre os direitos autorais de imagem e som lançando, vez por outra, com a suspeita do caráter duvidoso do trabalho de campo pelas assimetrias de poder que costumam regular o encontro entre o antropólogo e os grupos por ele pesquisado.

Portanto, vale retornar as formas de produção de conhecimento na Antropologia como saída possível para este debate na tentativa de evitar o aprisionamento de seus saberes e fazeres nos labirínticos caminhos da cultura da escrita tanto quando da cultura do pape ${ }^{26}$. Seja a proteção da propriedade intelectual da obra, com base nos direitos de autor; seja a defesa da inviolabilidade dos direitos de personalidade, que são intransmissíveis porque inerentes à própria pessoa humana, e inseparáveis dela, porque inatos, algo que esta por detrás deste debate em termos do pensamento antropológico, é idéia do que é, ou não, próprio daquele ou daquilo sobre o qual versa uma obra da cultura humana. No campo da produção do conhecimento antropológico, a defesa dos direitos de autor-escritor-etnógrafo sofre injunções da proteção aos direitos de imagem e som, inalienável daquele ou daquilo de que trata a obra etnográfica.

Assim, em se tratando da propriedade intelectual da obra antropológica, da defesa daquilo que lhe é próprio e a singulariza, sabe-se, entretanto, já a algum tempo, de que o que é

\footnotetext{
${ }^{25}$ Cf. Roger CHARTIER, A aventura do livro, do leitor ao navegador. Sao Paulo, UNESP, 1999, p.34.

${ }^{26}$ Ver a respeito Marcio DOCTORS (org) A cultura do papel, Rio de Janeiro, Casa da Palavra, Fundação Eva Kablin Rapaport, 1999.
} 
próprio da obra etnográfica é precisamente sua indeterminação quanto à situação de onde ela se origina, ou seja, do encontro etnográfico do antropólogo-autor com a sociedade que ele está pesquisando, a partir das tradições de pensamento que ele adota no interior de sua matriz disciplinar. Portanto, antes de se transpor o debate dos direitos de autor para a produção de conhecimento em Antropologia, talvez fosse necessário uma reflexão os ruídos que separam o antropólogo-autor de sua obra, como sendo aquilo que é próprio, de propriedade, do campo dos saberes antropológicos. Não se trataria assim de subjugar a defesa dos direitos de autor aos direitos de imagem e som, numa perspectiva de veneração ingênua à figura do "nativo" (própria $\left.d e . .{ }^{27}\right)$ como fonte da verdade etnográfica, o que pode ser nefasto para ele no sentido desta visão inscrever seu estado presente na eternidade de uma forma congelada. Nem tampouco se trataria de submeter os direitos de personalidade daquele e/ou daquilo aos direitos do antropólogo as sua obra, isto é, submetendo o outro ao que é próprio do intelecto do antropólogo.

Nos direitos autorais a lei prevê que só o autor pode alterar a sua própria obra. Entretanto, para cumprir este quesito, no que tange aos aspectos ético-morais que orientariam a defesa do direito autoral na produção de conhecimento em Antropologia, todo o autor de uma obra etnográfica não poderia prescindir da aceitação aqueles que dela foram objetos e sujeitos ainda que se reconheça, neste acordo, o seu caráter efêmero e mesmo frágil. Torna-se necessário se retornar a constatação de que os dados e informações que compõem a grande totalidade da produção de conhecimento em Antropologia têm por base a forma histórica que, naquele momento, adota a vida social onde se configura o fenômeno registrado ou capturado pelo antropólogo. Neste sentido, a integridade do pensamento do autor do qual resultaria a defesa da autenticidade da sua obra tanto quanto de seus direitos morais e patrimoniais sobre ela, na Antropologia, guardaria relações de estreitas de interdependência do tempo e do espaço com o encontro etnográfico acorrido entre o antropólogo e a sociedade por ele estudada, sofrendo sua a autenticidade de sua obra com as mutações, transformações e mudanças constantes daí advindas.

A defesa do direito autoral e dos direitos de imagem e som na produção de conhecimento audiovisual em Antropologia deve abarcar, assim, a dimensão ético-moral que orienta as falhas e hiatos que delimitam a prática do campo do antropólogo, e que nem sempre sujeita a jurisprudência da lei, da cultura da escrita, ainda que não se possa dela prescindir a esta altura das práticas culturais adotadas pela matriz antropológica. Neste ponto, as modalidades normativas de construção do texto etnográfico e as suas formas padronizadas de leitura usualmente apreendidas pelos antropólogos precisam ser re-pensadas no interior da Internet.

\footnotetext{
${ }^{27}$ Emprega-se aqui algumas das idéias desenvolvidas por Jean-Maire BENOIST, na obra Tyrannie du logos, Paris PUF, 1993, a propósito dos esforços do logos para reduzir tudo a um princípio de identidade, em especial o Capítulo. 6, Le propre comme généalogie de la divison du travail scientifique.
} 